\title{
Resolving Pronominal Ambiguity: Role of Contextual Constraints.
}

S. Montoya, G. Denhière and T. Baccino

\section{(2) OpenEdition \\ 1 Journals}

Electronic version

URL: http://journals.openedition.org/cpl/203

DOI: $10.4000 / \mathrm{cpl} .203$

ISSN: $1379-6100$

\section{Publisher}

Centre PsyCLÉ

Printed version

Date of publication: 1 August 2002

\section{Electronic reference}

S. Montoya, G. Denhière and T. Baccino, «Resolving Pronominal Ambiguity: Role of Contextual Constraints. ", Current psychology letters [Online], 2002/2, 8 | 2002, Online since 05 September 2003, connection on 08 September 2020. URL : http://journals.openedition.org/cpl/203 ; DOI : https:// doi.org/10.4000/cpl.203

This text was automatically generated on 8 September 2020.

(C) All rights reserved 


\section{Resolving Pronominal Ambiguity: Role of Contextual Constraints.}

S. Montoya, G. Denhière and T. Baccino 